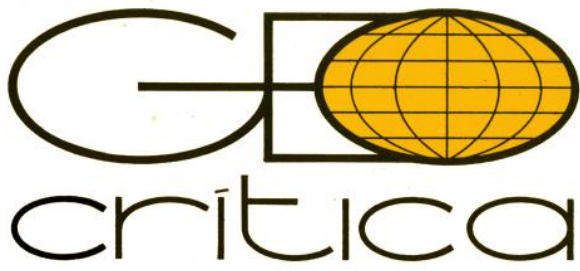

DOI: https://doi.org/I0.1344/ara2021.260.36990

\title{
DISEÑO Y FUNCIÓN DE LAS SALAS HIPÓSTILAS CLÁSICAS. EL TRIÁNGULO EGIPTO, PERSIA Y GRECIA
}

\author{
Manuel-Blas García Ávila \\ Artista plástico y proyectista \\ manuelblasg@gmail.com
}

Diseño y función de las salas hipóstilas clásicas. El triángulo Egipto, Persia y Grecia (Resumen) Las salas hipóstilas clásicas nos han dejado un gran legado arquitectónico, no solo por su grandiosidad y su refinada estética, sino por la coherencia de cada espacio con la función o el uso a que se destinó. Demostrar esta unidad orgánica, esta interacción entre lo estético y lo utilitario desde el principio de la arquitectura, es el objetivo que nos hemos propuesto en este artículo. Historiadores y arqueólogos estudiosos del tema, como D. S. Robertson, J. J. Pollit o J. Pijoan, nos han proporcionado un amplio marco teórico, mediante el cual ha sido posible examinar las relaciones entre el diseño y la función de las salas hipóstilas clásicas. Nuestro análisis lo hacemos partiendo del Complejo Funerario de Zóser, en Egipto, en el III milenio a. C., pasando por la Persia Aqueménida y llegando hasta la Grecia helenística.

Palabras clave: Diseño y función; Salas hipóstilas clásicas; Egipto Persia y Grecia.

\section{Disseny i funció de les sales hipòstiles clàssiques. El triangle Egipte, Persia i Grècia (Resum)}

Les sales hipòstiles clàssiques ens han deixat un grat llegat arquitectònic, no només per la seva grandiositat i refinada estètica, sinó també per la coherència de cada espai amb la funció o l'ús al que va ser destinat. Demostrar aquesta unitat orgànica, aquesta interacció entre la vesant estètica i la utilitària des del principi de l'arquitectura, és l'objectiu que ens hem proposat en aquest article. Historiadors i arqueòlegs estudiosos del tema, com D. S. Robertson, J. J. Pollit o J. Pijoan ens han proporcionat un ampli marc teòric, mitjançant el qual ha estat possible examinar les relacions entre el disseny y la funció de les sales hipòstiles clàssiques. Fem el nostre anàlisi partint del Complex Funerari de Zòser, a l'Egipte, en el III mil·leni a. C., passant per la Pèrsia Aquemènida i arribant fins a la Grècia hel·lenística.

Paraules clau: Disseny i funció; Sales hipòstiles clàssiques; Egipte, Pèrsia i Grècia. 
Design and function of classic hypostyle rooms. The Triangle Egypt, Persia and Greece (Abstract)

The classic hypostyle rooms have left us a great architectural legacy, not only because of their grandeur and their refined aesthetic, but because of the coherence of each space with the function or use it was destined. Demonstrating this organic unit, this interaction between the aesthetic and the utilitarian from the beginning of architecture, is the objective we have proposed in this article. Historians and archaeologists scholars of the subject, such as D. S. Robertson, J. J. Pollit or J. Pijoan, have provided us with a wide theoretical framework, through which has been possible to examine the relationships between design and function of classical hypostyle rooms. Our analysis we do it based on the Funerary Complex of Zoser, in Egypt, in the III millennium a. C., passing through the Achaménida Persia and reaching Hellenistic Greece.

Key words: Design and function; Classic Hypostile Rooms; Egypt, Persia and Greece.

\section{Introducción}

En la obra de arte, desde sus comienzos clásicos, existe una relación entre los conceptos "contenido" y "forma" en los que "el origen no altera el valor plástico o estético"1 y, dependiendo de las características propias de la obra, suele resultar dominante uno de ellos; pero lo deseable es que haya una interacción y una coherencia entre ambos, como manifestó Louis H. Sullivan en su sentencia racionalista "la forma sigue la función". Igual en la arquitectura, que, desde su origen, por su función práctica, ha sido y es necesariamente un arte y una ciencia, la forma, el aspecto externo, por sus proporciones y belleza puede deslumbrar, pero su uso es su función necesaria.

Se puede afirmar que, entre las artes tradicionales, la arquitectura por no ser un arte solo representativo como la pintura o la escultura, no ha perdido su función, ya que su habitabilidad le da una utilidad material, un uso, características intrínsecas de la arquitectura. Por consiguiente, las salas hipóstilas de los edificios clásicos que analizaremos, en cualquiera de sus estilos han de ser perfectamente habitables.

Marco Lucio Vitruvio (81 al 15 a. C.) en su "Primer Libro de Arquitectura" exigía a los arquitectos romanos:

talento y afición al estudio...tener aptitudes para el Dibujo; conocer la Geometría; no estar ayuno en Óptica; ser instruido en Aritmética y versado en Historia; haber oído con aprovechamiento a los filósofos; tener conocimiento de Música; no ignorar la Medicina; unir los conocimientos de la Jurisprudencia y los de la Astrología y movimiento de los astros².

La sala hipóstila es, según la definición historiográfica de los griegos (hypo, que significa "bajo", y stylos "columna"), un recinto arquitectónico cubierto y de techumbre plana, sostenido por columnas arquitrabadas. El arquitrabe -sinónimo de dintel- es la parte inferior de un entablamento plano, que carga sobre los capiteles de las columnas y es habitualmente horizontal.

Es muy probable que su construcción y difusión en la época clásica, se haya dado porque en Grecia no conocían el arco y la bóveda, y aunque los egipcios y los persas los conocieran porque sus vecinos asirios y babilonios los construían con ladrillos desde el milenio IV a. C.-, estos tampoco los utilizaron. En su formidable arquitectura, ni los egipcios, los persas o los

\footnotetext{
${ }^{1}$ García Ávila, 2007 <http://www.ub.edu/geocrit/b3w-742.htm>.

${ }^{2}$ Vitruvio, 1982, p. 6.
} 
griegos, utilizaron estas formas curvas, por lo que las salas hipóstilas, con sus techos adintelados, en los tres casos, son históricamente sus primeras formas monumentales habitables ${ }^{3}$.

Otra característica fundamental de las salas hipóstilas, y un gran mérito, es su originalidad, en cualquiera de las tres morfologías, a saber, la egipcia, la persa y la griega, esta última, lo hacemos en su vertiente civil, muy poco conocida. Los tres usos y funciones para los que se construyeron dependiendo del lugar- la religiosa-funeraria egipcia, la aristocrática persa y la político-artístico-civil griega- nos demuestra como el espíritu creador humano ha sabido someter para los diferentes usos, las formas inspiradas -como veremos- en unos casos en la naturaleza y la mitología, y en otros, en la abstracción geométrica ${ }^{4}$.

Así pues, el eje sobre el que gira nuestro análisis, se centra en la interacción entre el uso, o sea la función y el diseño de las salas hipóstilas más características, considerando que dieron origen a las formas, los diseños y los estilos que adquirieron estas edificaciones.

Dada la proliferación histórica de edificios que detentan estas formidables edificaciones, este examen no podrá ser exhaustivo. Vamos a seleccionar dos salas egipcias, dos persas y otras tres griegas, que son muy representativas y por lo tanto idóneas para nuestro planteamiento. Algunas de ellas son el núcleo de la edificación, pero otras forman parte de construcciones principales, en las que están integradas, como templos, palacios o núcleos civiles.

Estructuramos este artículo en cuatro apartados, además de esta introducción y de las conclusiones. Inicialmente reflexionamos sobre la difusión y la interrelación de estilos que comprenden las salas hipóstilas en Egipto, Persia y Grecia, tres grandes núcleos arquitectónicos clásicos perfectamente identificables, que representan los vértices de un triángulo geográfico que delimita nuestra investigación (figura 1). A continuación, elaboramos un análisis sobre las salas hipóstilas más representativas. Cronológicamente el primer vértice lo ocupa Egipto, paradigma de la arquitectura monumental hipóstila, de utilidad religiosa y funeraria; el segundo lo situamos en Persia, con los palacios aqueménidas y sus apadanas y el tercero en la Grecia civil, desde el espléndido Pericles hasta la época helenística, considerada ésta, desde la muerte de Alejandro Magno, en el año 323 a. C. hasta la de Cleopatra VII, el año 31 a. C.

\footnotetext{
${ }^{3}$ ArtEEspaña <https://www.arteespana.com/arquitecturamesopotamica.htm>.

${ }^{4}$ Masdearte.com <https://masdearte.com/especiales/louis-sullivan-la-forma-sigue-la-funcion/> .
} 
Figura 1. Triángulo Egipto, Persia y Grecia

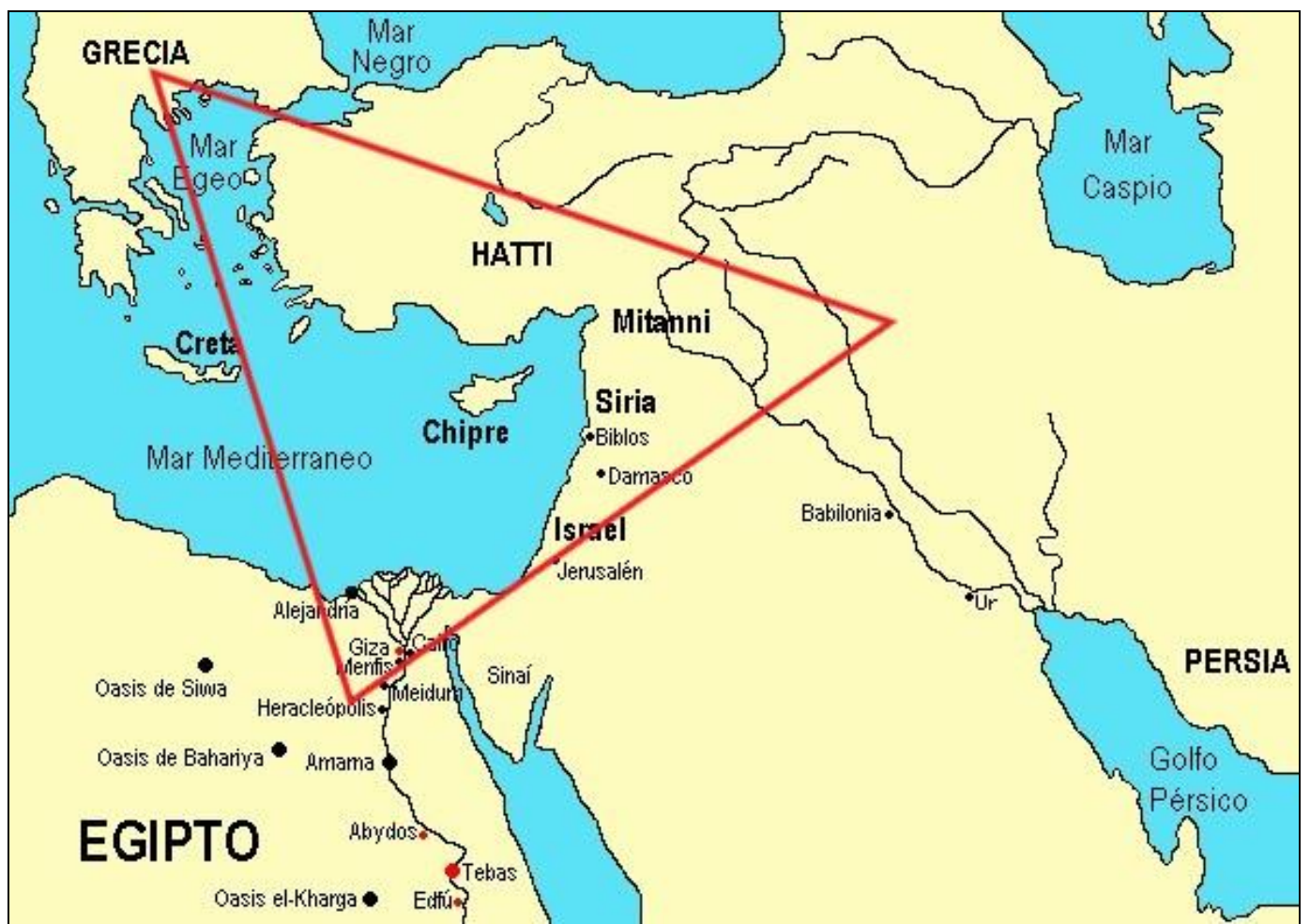

Fuente: Elaborado por el autor.

La metodología se basa en una exhaustiva revisión bibliográfica en obras clásicas, como las de Donald Struan Robertson, Joseph Pijoan, Jerome Jordan Pollit y Moses I. Finley, también una minuciosa búsqueda y selección de páginas Web que publican estudios e informaciones sobre las salas hipóstilas egipcias, pérsicas y griegas construidas entre los milenios III y I a. C.

Como introducción al tema, haremos un breve análisis de cómo se influyeron mutuamente estas tres culturas.

\section{La difusión e interrelación de estilos que comprenden las salas hipóstilas egipcias, pérsicas y griegas}

Aunque la originalidad es en todos los casos incuestionable, es importante entender que hubo una interrelación cultural entre los tres polos de creación que analizamos. La arquitectura egipcia ejerció una evidente influencia en la Persia clásica, singularmente en las Apadanas (salas hipóstilas integradas en los palacios) como el caso del capitel campaniforme invertido (figura 2), que incorporaron como basa de las columnas, o los detalles florales añadidos a los fustes y los capiteles persas. 
Figura 2. Ruinas persas con basas de columnas diseñadas copiando los capiteles campaniformes egipcios, pero invirtiéndolos

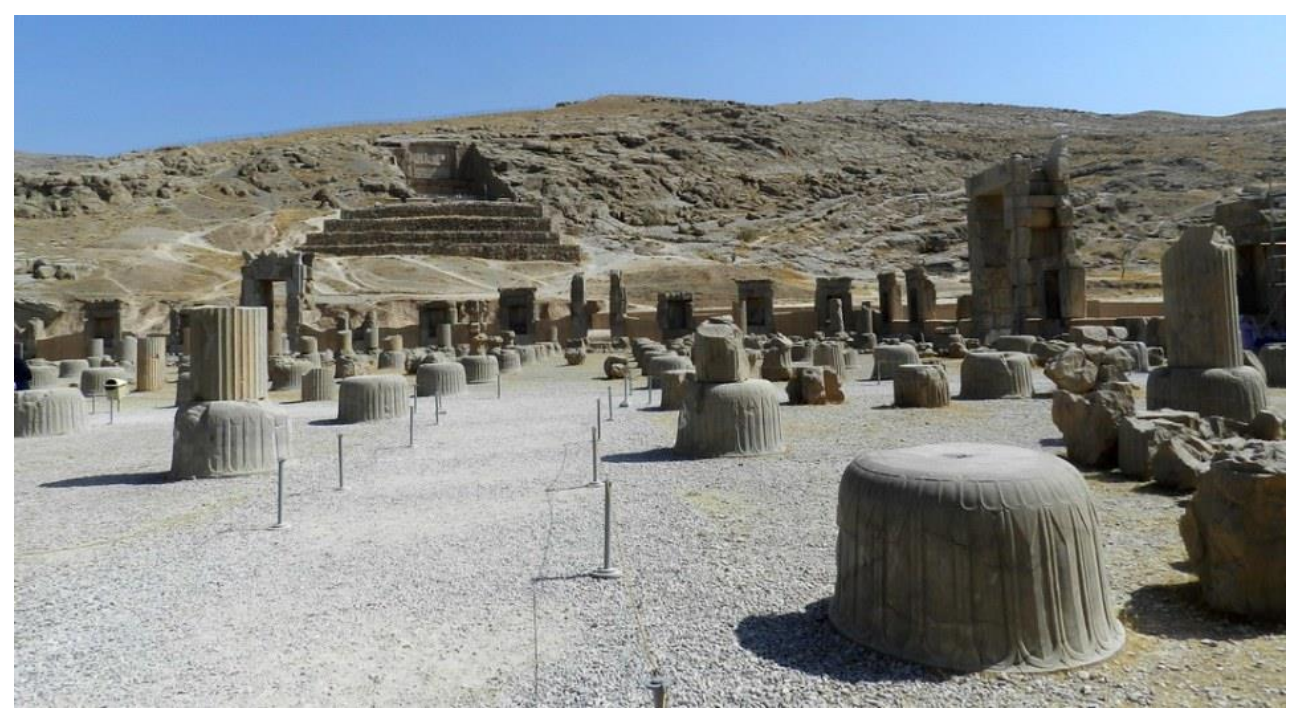

Fuente: Blog de viajes <https://micamara.es/persepolis/>.

También es egipcia la influencia en la Grecia Helenística del Asia Menor (hoy Turquía) como en el ejemplo del Templo de Artemisa Leucofriene en Magnesia, obra maestra de Hermógenes, donde la naos "quedaba separada del exterior por medio de columnas enlazadas hasta cierta altura mediante un muro, como era costumbre en Egipto".

Asimismo, Persia y Grecia efectuaron trascendentes intercambios formales, a pesar del vaivén de las frecuentes y devastadoras guerras mutuas de conquista -que además de causar grandes pérdidas humanas- provocaron desastres irreparables en la cultura y el arte.

Aun así, esta "relación" produjo una simbiosis evidente en las artes y específicamente en la arquitectura del ecléctico arte medo-persa, incorporando y adaptando a sus edificaciones más sobresalientes, elementos del arte asirio, egipcio y griego jónico del Asia Menor. A la inversa, las inmensas salas hipóstilas de los palacios aqueménidas persas, influyeron en el arte griego civil, por ejemplo, en la estructura de la cubierta del Odeón de Pericles, que es de similares características.

También, al fin, es incontestable que la Hélade (nombre con el que denominaban los antiguos griegos a su país) fue fundamento y modelo de la trascendental cultura clásica, y específicamente, la arquitectura, que fue asumida formalmente por la Roma Imperial, desde Augusto y Flavio, "de puro espíritu griego". Los romanos incorporaron el arco, la bóveda y la cúpula, nuevas morfologías edificativas que desarrollaron y propagaron, habiendo sobrevivido un gran número de edificaciones, puentes y acueductos de la época imperial. Al respecto, Donald Struan Robertson comprendiendo las nuevas funciones y usos de estas aportaciones a la arquitectura, afirma "los romanos fueron los primeros constructores de Europa, y quizá también del mundo, que supieron apreciar completamente las ventajas del arco, la bóveda y la cúpula"7.

\footnotetext{
${ }^{5}$ Pijoan, 1964, vol. I, p. 216.

${ }^{6}$ Pijoan, 1964, vol. I, p. 276.

${ }^{7}$ Robertson, p. 220.
} 


\section{Egipto y la arquitectura religiosa-funeraria}

En Egipto el período cronológico en que se construyen los templos hipóstilos es amplísimo, dura unos tres milenios, desde Sety I y Ramsés II, hasta la dinastía Ptolomeica; pero los conceptos estructurales y su grandiosidad se mantuvieron invariables, con salas hipóstilas, en plantas longitudinales generalmente simétricas. Excepcionalmente, en algunos casos como el templo de Sety I en Abidos, la planta es en forma de L, aunque con una distribución clásica.

Para asimilar la peculiaridad de sus valores estéticos es importante entender el papel fundamental que juega la religión en su fusión con el poder terrenal, con el faraón de modo que esta simbiosis marca el arte en el que se desarrolla. En este punto es oportuno el razonamiento del sociólogo Herbert Read, que en su análisis sobre la función del arte y su utilización política y religiosa disocia el impulso creativo de la función de representación, que ha sido el motor del arte durante mas de tres milenios, exponiendo que "ni la religión es esencial para el arte, ni el arte lo es para la religión. El impulso estético es inherente al hombre y el único problema consiste en saber hasta qué punto una religión educa o inhibe tal impulso" 8 .

Sobre la estricta relación del poder político con el religioso en Egipto, el arquitecto e historiador del arte Josep Pijoan nos refiere en su Historia del Arte, que

Durante su evolución milenaria el arte egipcio solo sufrió una grande y verdadera sacudida en tiempo del faraón herético Amenhofis IV, nieto del gran Tutmés. Tomó el nombre de AkenAtón y quiso introducir la adoración del gran disco solar. La nueva religión de este soberano de la XVIII dinastía, era más naturalista que el misticismo, simbólico y geométrico, del culto de $\mathrm{Ra}^{9}$.

Y también nos alecciona sobre las divisiones cronologías de los estilos arquitectónicos egipcios, planteando como muy arriesgado su distinción. Literalmente nos dice: "La columna presenta varias formas que coexisten en todas las épocas" ${ }^{10}$.

En Egipto, igual que su arquitectura, sus divinidades se mantienen prácticamente invariables hasta la época Ptolomeica e incluso romana, puesto que los dioses siguen siendo los mismos, pero varía su representación, porque desaparecen las personas con cabezas zoomórficas. Podemos interpretar en estos templos una contradicción estructural, producida por la doble función que desarrollaron, por un lado, la del poder, mediante las salas hipóstilas, con una presencia exterior espectacular, arquitectónicamente gigantesca, y por otro, la utilidad de la representación mística, en lo más cerrado y angosto, lo más oculto, inaccesible para la población, donde se situaban los santuarios con la imagen del dios o dioses titulares del templo.

Por esta razón, la sala hipóstila, fundamental en el templo egipcio, que daba acceso al santuario o los santuarios, estaba siempre situada a continuación de la sala hípetra, un amplio espacio del templo a modo de plaza porticada, a la que tenía acceso la población. Sus muros y columnas, decorados mediante representaciones en bajorrelieves policromados, pinturas e inscripciones jeroglíficas, y se deben a la elucubración de los egipcios sobre el origen de su mundo, describiendo que en un principio solo había "un dios cocodrilo" que sudó y de ese

\footnotetext{
${ }^{8}$ Read, 1973, p. 90.

${ }^{9}$ Pijoan, 1964, vol. I, p. 70.

${ }^{10}$ Pijoan, 1964, vol. I, p. 68.
} 
sudor surgió el río Nilo, que produjo la vegetación y la vida. De esta idea metafísica surgió Egipto, y Egipto es el Nilo.

En consecuencia, las columnas gigantescas de las salas hipóstilas de sus templos, que formalmente simbolizan tallos de loto, con el fuste fascicular, formado por tallos de la flor, tienen su origen en la flora del Nilo. Sus capiteles papiriformes cerrados o abiertos, estos últimos también conocidos como campaniformes (bajo Egipto), lotiformes (alto Egipto) o palmiformes - por su forma de copa de palmera- corroboran este origen (figura 3). Debemos citar por su excepcionalidad, los capiteles con la efigie de la diosa Hathor conocidos como hathóricos.

Figura 3. Columnas egipcias con diferentes tipos de capiteles fitomórficos
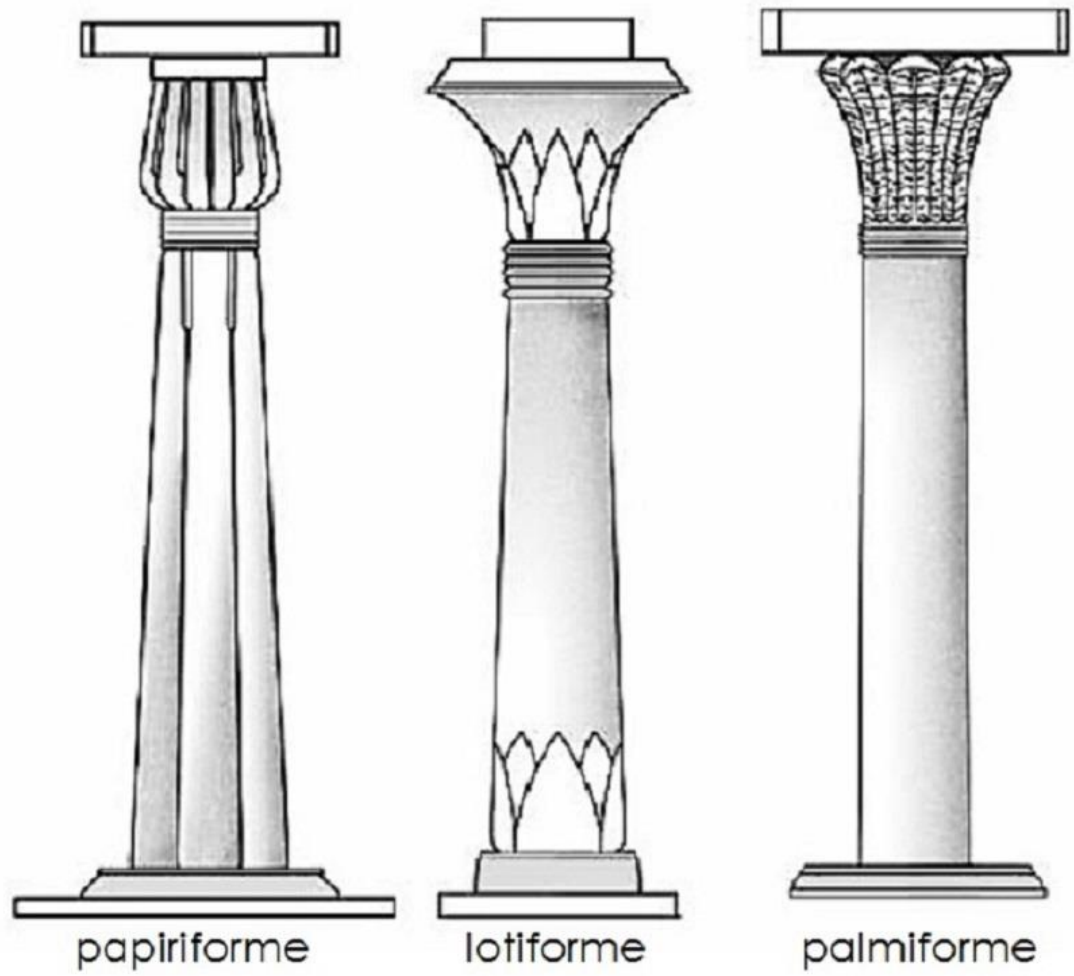

Fuente: Glosario ilustrado de arte arquitectónico <https://www.glosarioarquitectonico.com/wpcontent/uploads/2015/12/columnas-egipcias-1.jpg $>$.

La característica fundamental de estas salas es el techo horizontal, con grandes losas colocadas directamente sobre las columnas por medio de arquitrabes -y como dijimos antesel capitel fitomórfico. También es una singularidad que ha resultado trascendental, el hecho de que, en los tres milenios de edificaciones, no hubiera cambios significativos en su evolución, lo que hizo que la arquitectura faraónica permitiera ampliaciones y rehabilitaciones acometidas por dinastías sucesivas ${ }^{11}$.

\footnotetext{
11 Información disponible en <https://historia.nationalgeographic.com.es/a/templo-karnak-gran-santuario-
} amon_6312/6>. 
Es por esta razón que Egipto con su colosal monumentalidad, es paradigma en el objeto estudiado en este artículo, la función y el diseño de las salas hipóstilas. Edificadas desde el milenio III a. C., destacan las siguientes salas hipóstilas egipcias:

- del formidable complejo de Zóser, construido por Inhotep, primer arquitecto conocido de la historia,

- del templo dedicado a Amón en Karnak,

- del templo dedicado a Bastet en Bubastis,

- del templo de Mentuhotep II,

- de la reina Hatshepsut, de Amón en Luxor,

- del Ramesseum, situado en la necrópolis de Tebas,

- del templo dedicado a Hathor en Dendera, etc.

Las últimas salas hipóstilas edificadas en Egipto pertenecen a la dinastía griega, que abarca desde Ptolomeo Sóter (general de Alejandro Magno), hasta Ptolomeo XIII (51-47 a. C.) y la helenística Cleopatra VII. Sobresalen las salas hipóstilas tolomeicas de la diosa Hathor representada con orejas zoomórficas en sus capiteles- en Dendera, la de Khnum en Esna y la de Kom Ombo.

\section{Escribe Isaac Asimov que}

Ptolomeo Sóter puso los fundamentos para hacer de su capital, Alejandría, un centro del saber; a ella invitó a los sabios del mundo griego con la promesa de sostén financiero y de oportunidades para efectuar ininterrumpidos estudios. Como el centro fue dedicado a las Musas, las diosas griegas del saber, se le conoce como el Museo ${ }^{12}$.

Debido a las limitaciones propias de este artículo solo analizaremos dos templos: el de Amón en Karnak por ser el mayor de los construidos en Egipto y el de Hathor en Dendera, por su sensualidad.

\section{Templo de Amón en Karnak}

En este primer vértice, tomamos como ejemplo el Templo dedicado a Amón en Karnak. Analizando su función, vemos que la sala hipóstila de este templo era la estancia posterior a la zona hípetra, que consistía en un gran patio porticado, al que tenía acceso la población común, la multitud. Esta sala hipóstila se puede definir como un enorme espacio adintelado, al que solo accedían las personas relacionadas con el templo, los sacerdotes y el faraón, que continuarían este recorrido hasta las estancias sagradas.

El templo de Amón es modelo en nuestro análisis, para entender como en la arquitectura templaria egipcia, las salas hipóstilas de hecho, detentaban un doble uso, como exhibición y demostración de la magnificencia del poder terrenal del faraón, y como acceso de las minorías aristocráticas y religiosas al santuario o sancta sanctorum, la zona oculta y mística, donde estaban, la naos (estancia) con la divinidad y la sala de la barca ${ }^{13}$.

\footnotetext{
12 Asimov, 2011, p. 328.

${ }^{13}$ ArtEEspaña <https://www.arteespana.com/templosegipcios.htm>.
} 
Esta sobrecogedora sala hipóstila del templo de Amón, era un espacio que medía 53 metros de fachada por 102 metros de fondo y el techo lo sostenían (porque ha desaparecido) 134 columnas espectaculares.

Simbólicamente, siguiendo el mimetismo con la naturaleza cercana que ya comentamos, del mismo modo que sólo con la luz solar las plantas abren sus cálices, sólo los capiteles papiriformes de las columnas centrales -por recibir luz- son abiertos, mientras que los cálices de los capiteles de las columnas laterales, sumidas en la penumbra, están cerrados (figuras 4 y $5)$.

Figura 4. Maqueta de la sala hipóstila del Templo de Amón en Karnak

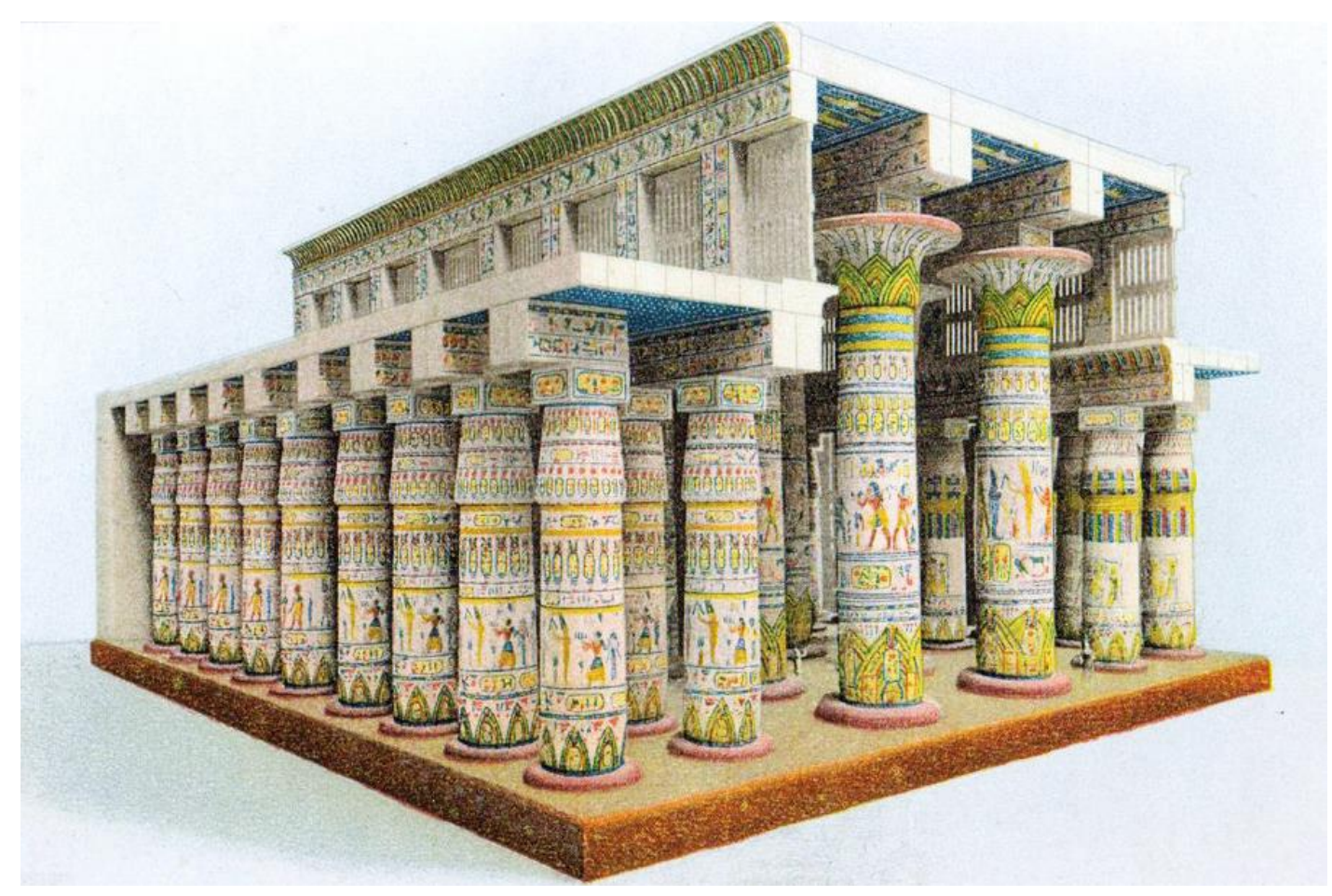

Fuente: Metropolitan de Nueva Cork <https://www.hisour.com/es/hypostyle-31915/>

Analizando estas proporciones Josep Pijoan afirma que:

las 12 columnas de la nave central, (que elevan el techo hasta los 23 metros), son todas ellas de igual diámetro que la Columna de la Plaza Vendôme de París, por lo que una catedral gótica cabría holgadamente dentro de este espacio interior, lo que la convierte en una obra excepcional dentro de la Historia del Arte $^{14}$.

Este templo, edificado entre los años 2200 y 360 a.C. contiene otros templos menores, capillas y un lago sagrado. Los principales faraones que intervinieron en su edificación ampliación y restauración a lo largo de los siglos, fueron Hatshepsut, Sety I, Ramsés II y Ramsés III.

\footnotetext{
${ }^{14}$ Pijoan, 1964, vol. I, p. 67-68.
} 
Este sistema constructivo de iluminación, que caracterizó las salas hipóstilas egipcias, mediante cubiertas a dos niveles, fue posteriormente utilizado, por ejemplo, en las basílicas civiles romanas Porcia, Emilia y la de Majencio y Constantino. También se aprecia este diseño arquitectónico en las catedrales góticas, como las de León y Milán, o muy posteriormente con la arquitectura funcionalista del The Crystal Palace de Londres y del Palacio de Cristal del Retiro de Madrid.

\section{Templo de la diosa Hathor en Dendera}

Es uno de los templos mejor conservados de Egipto y está dedicado a esta diosa del amor, la fertilidad, el erotismo etc. Situado en Dendera (ciudad de la orilla occidental del rio Nilo, a 60 kilómetros al norte de Luxor), su construcción actual es del período ptolemaico tardío (entre el año 30 a. C y el 14 d. C). Sus autores fueron Ptolomeo XII y Cleopatra VII, grecomacedonia de origen, última gobernante de la dinastía ptolomeica egipcia. Por esta clara influencia griega, este templo, es una edificación que posee una admirable unidad funcional, constructiva y de estilo (figura 5). Se comprobó por las inscripciones halladas que su edificación fue realizada sobre un templo mucho más antiguo, de la época del faraón Thutmose III (1479 a 1425 a. C.).

Figura 5. Fachada del Templo de Hathor en Dendera

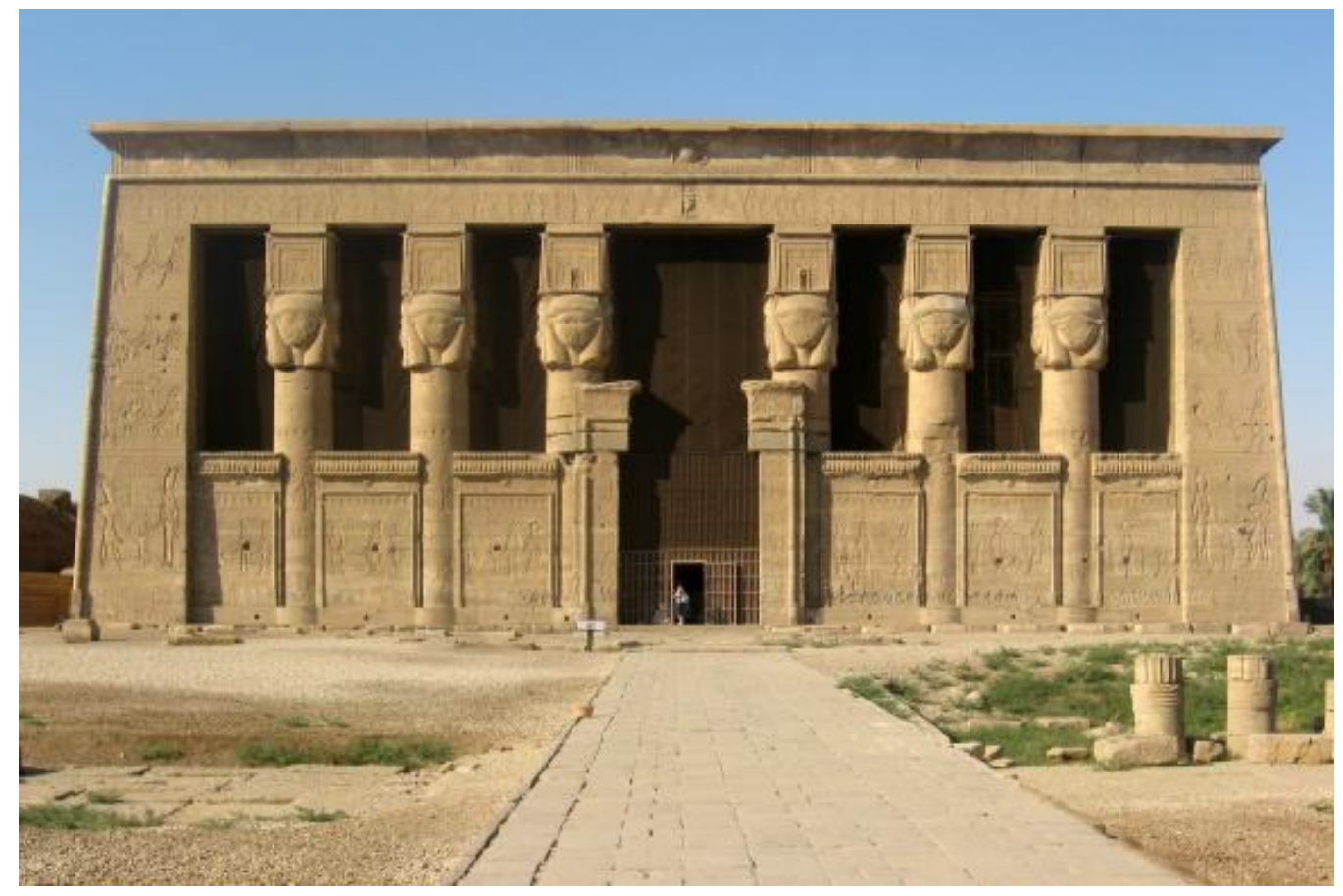

Fuente: 〈https://es.wikipedia.org/wiki/Templo_de_Dendera\#/media/Archivo:Dendera_7_977.PNG>

Su colosal fachada está sostenida por 6 columnas de capiteles hathóricos con todos los intercolumnios cerrados a media altura menos el central, mas amplio que conforma el acceso al templo. Las columnas de la fachada están alineadas con las de la primera sala hipóstila, la exterior, por lo que las consideramos integradas en su estructura. A través de esta sala, accedemos a una segunda sala hipóstila mucho menor, alrededor de la cual se encuentran las zonas administrativas, y a continuación, accedemos a la sala de ofrendas y al santuario. 
Esta primera sala hipóstila de 42,5 metros de ancho y 28,4 metros de fondo, con capiteles también hathóricos (figura 5), la añadió al templo posteriormente, el emperador Tiberio, y está formada por 18 columnas más, dispuestas en 3 filas de 6 , quedando el intercolumnio central de acceso también más amplio. El techo, situado a 15 metros de altura, está decorado con escenas celestes, en las que aparece la diosa Nut -la Tierra- trayendo el Sol al mundo. La segunda sala hipóstila que encontramos a continuación está formada por dos hileras de 3 columnas, una a cada lado, y mediante ella tenemos acceso a múltiples dependencias laterales y a la sala de ofrendas.

Su planta observa una absoluta simetría, característica de esta arquitectura, en la que destaca la primera sala hipóstila, seguida de la segunda y del santuario principal (figura 6).

Figura 6. Planta del templo de Hathor en Dendera

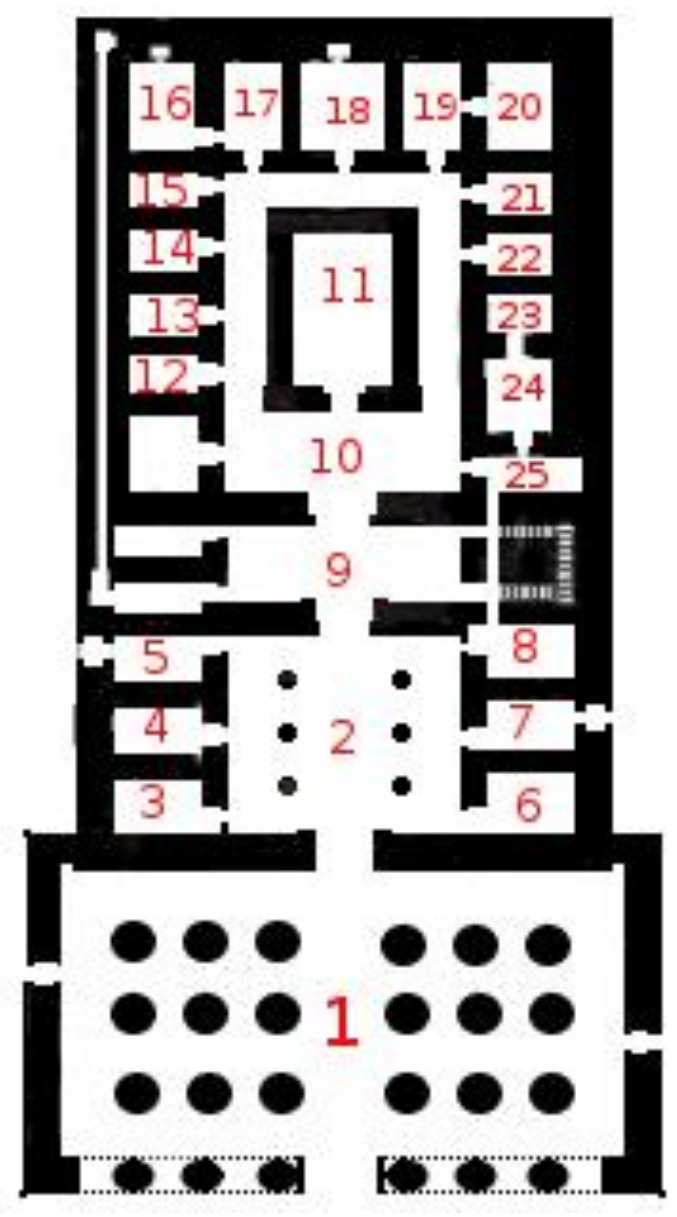

Fuente: 〈https://es.wikipedia.org/wiki/Templo_de_Dendera>.

Distribución de la planta: 1. Primera sala hipóstila; 2. Segunda sala hipóstila; del 3 al 10. Accesos y dependencias; 11. Santuario principal; del 12 al 22. Otros santuarios; del 23 al 26. Otros accesos y espacios. 
Las columnas realizadas en caliza, con plintos circulares, se alzan con el fuste liso, pero muy decorado con personajes, escenas y delicados jeroglíficos, colocados muy ordenadamente en zonas delimitadas horizontalmente. Una singularidad formal de la diosa Hathor, es que mientras que a los faraones y dioses egipcios eran representados de perfil, igual en pinturas que en esculturas o bajorrelieves, ella era mostrada de frente (figuras 5 y 7 ).

Figura 7. Detalle de las Columnas hathóricas en el Templo de Hathor

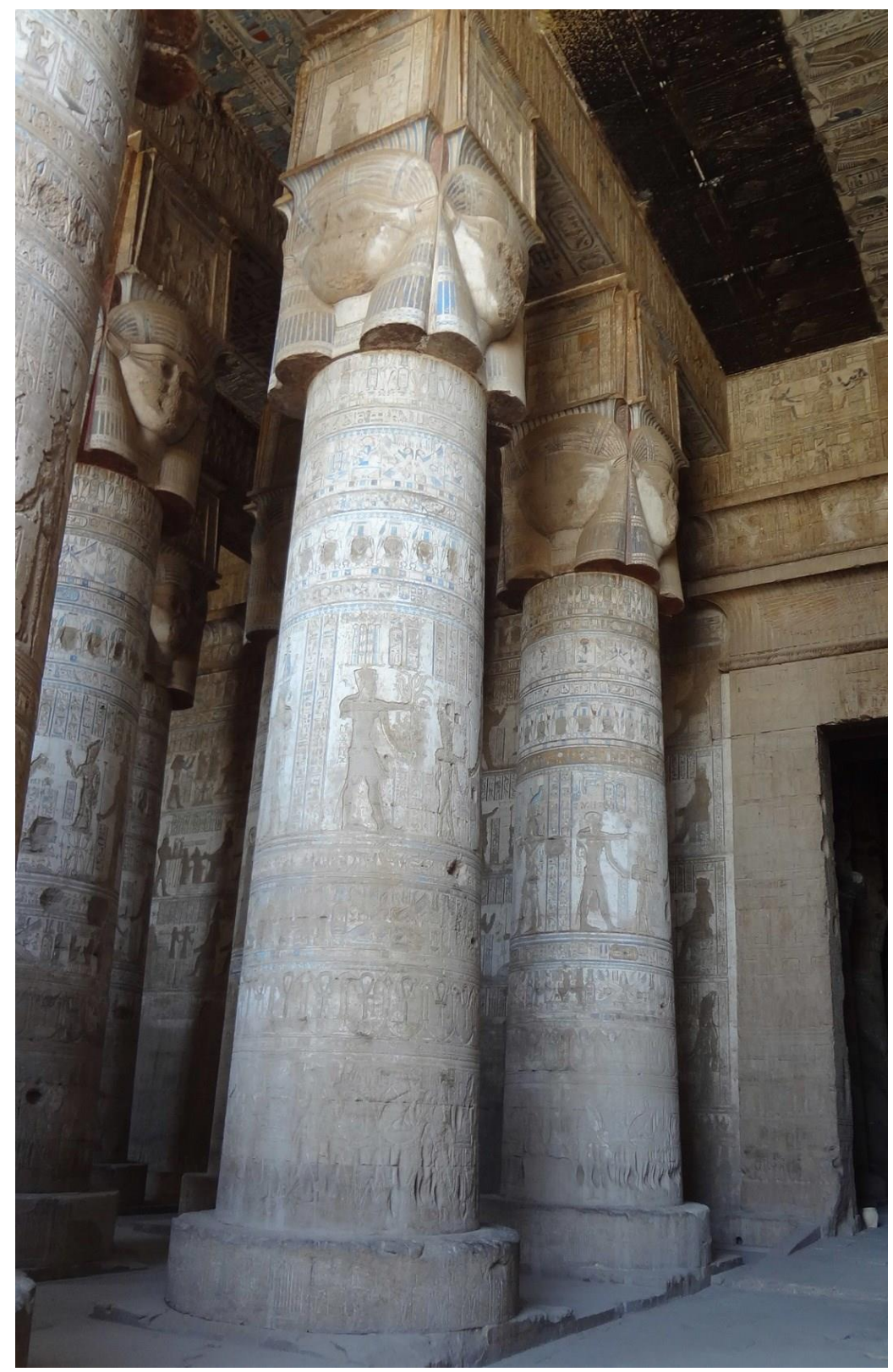

Fuente: Francisco López, 2003 <https://megaconstrucciones.net/?construccion=templo-dendera>. 
El capitel con la efigie de Hathor está diseñado en dos cuerpos superpuestos iguales, el inferior que representa frontalmente a la diosa con una morfología cuádruple, es decir, en los cuatro lados que conforman el capitel, y el cuerpo superior, es un gran ábaco geométrico, un cubo regular. La diosa se presenta con los rasgos de una mujer joven fácilmente identificable, tanto por las orejas zoomórficas (concretamente de vaca) como por los cuernos que rodean su arco solar. El uso que se daba a este templo era similar a la de los demás, pero, por ser dedicado a una deidad femenina, con su sensual diseño, es uno de los templos más hermosos y enigmáticos.

\section{Persia y la arquitectura aristocrática palaciega}

Nuestro segundo vértice geográfico lo hemos situado en la Persia clásica, donde la sala hipóstila principal de los palacios construidos por Ciro II el Grande en el siglo VI a. C. se conoce por apadana. La arquitectura habitable persa es fundamentalmente palaciega, siendo casi inexistentes los templos, ya que en esta cultura el poder político domina al religioso. Además, la primera dinastía persa, conocida como aqueménida, llevaba a cabo una política de tolerancia religiosa y respetaba las creencias de los pueblos conquistados. Pijoan nos comenta al respecto que, en la cumbre de la montaña donde estaba situada la ciudad de Persépolis, "están todavía los altares para el fuego sagrado, que era el culto de los persas, únicos monumentos religiosos de la Persia antigua"15.

La apadana es donde el rey recibe fastuosamente a sus súbditos y legaciones extranjeras. Eran edificaciones cuya arquitectura fue tomada fundamentalmente de las salas hipóstilas egipcias, y sus esbeltas columnas tienen la basa (parte inferior) inspirada en el capitel egipcio campaniforme, pero colocado invertido y con detalles floridos en los capiteles (remate superior).

Por estas aristocráticas funciones, la morfología y diseño de estas salas hipóstilas es exuberante. En consonancia con esta suntuosidad, también son más altas que el resto de las edificaciones. En el origen de su diseño se observan las influencias hititas, y sobre todo jónicas, porque el fuste (zona media) está estriado, su entrada precedida de un gran propileo (porche) y decorada con volutas (espirales del orden jónico), sus complicados capiteles zoomórficos constituidos por prótomes, representaciones de animales reales o monstruos mitológicos.

Las tres mayores apadanas persas se situaban en los palacios aqueménidas de Pasagardas, Susa y Persépolis, cuyos restos podemos admirar in situ y en varios museos. La más antigua era la de Pasargadas, obra de Ciro II el Grande, pero quizá la más famosa, era la de Persépolis, diseñada por Darío y construida por Jerjes I. También observamos que el Palacio Shaour contenía una importante sala hipóstila. En cualquier caso, nos limitamos a analizar las apadanas de Susa y Persépolis, que poseían estructuras de madera de cedro, y cuyo diseño fue referencia para edificaciones de similares características en la Grecia clásica, como el Odeón de Pericles, que estudiaremos en el vértice griego.

\footnotetext{
${ }^{15}$ Pijoan, 1964, vol. I, p. 108.
} 


\section{Palacio de Susa}

La milenaria ciudad de Susa, que fue capital del reino de Elam, en este constante trasiego histórico, vivió épocas de gran poder. En el siglo XII a. C. los botines de guerra que provenían básicamente de Babilonia, incluyeron la estela que contiene inscrito el segundo conjunto de normas empíricas, a modo de leyes, de la historia -el primero fue de Ur-Nammu- conocido como el Código Hammurabi (1792-1750 a. C.).

En líneas generales, el palacio de esta gran ciudad fue comenzado por Darío I en torno al año 510 a.C. y continuado por su hijo Jerjes I. Cambises II, que hizo trasladar la capital del imperio desde Pasargadas a Susa y al fin, el palacio fue completado por Artajerjes I, pero durante su reinado el palacio sufrió un incendio, razón por la que posteriormente fue reconstruido por Artajerjes II.

$\mathrm{Su}$ arquitectura se inspira en los palacios del período neobabilonio en lo que se refiere a la organización funcional de las salas en la Casa de Rey, con una sucesión de espacios interiores alineados. Pero presenta también originalidades, como las salas hipóstilas cuadradas, que sirvieron de modelo para los palacios de Persépolis (figura 8).

\section{Figura 8. Palacio de Susa}

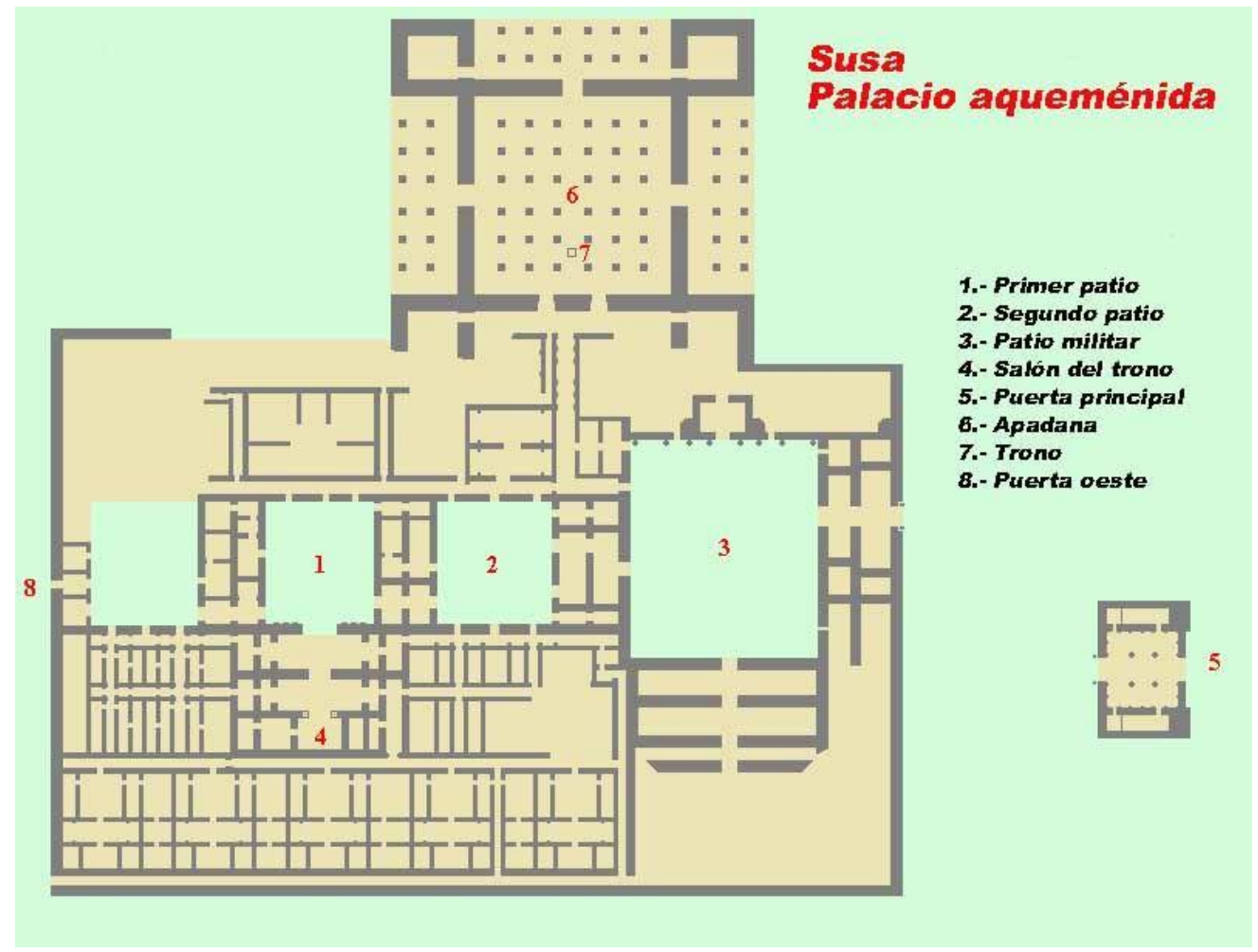

Fuente: <http://apuntes.santanderlasalle.es/arte/mesopotamia/arquitectura/persa/susa_palacio.htm>.

Desde el punto de vista de los materiales, se ve la mezcla de éstos, que es la técnica característica en Mesopotamia (adobes y ladrillos esmaltados), y de la de los montañeses persas (madera y piedra). 
La Apadana, utilizada como sala de audiencias real -de aquí su magnificencia- se construyó al norte del palacio de Susa. Se trata de un gran edificio -12.000 metros cuadrados- de base regular, con 109 metros de lado; se organiza en torno a una magnífica sala central hipóstila y también cuadrada de 58 metros de lado, es soportada por seis hileras de seis columnas cada una, que tienen la característica jónica de las estrías en el fuste y las volutas en el capitel de protón de toro, situados a una altura de 19 metros.

Estas columnas son una constatación de que los arquitectos griegos colaboraron formalmente en la construcción de los grandes edificios persas. Podemos admirar una muestra de este impresionante capitel de la Apadana del palacio de Darío, en Susa, en la sala de antigüedades de Oriente Próximo del Museo del Louvre (figura 9).

Figura 9. Capitel de protón de toro de la Apadana del palacio de Darío en Susa

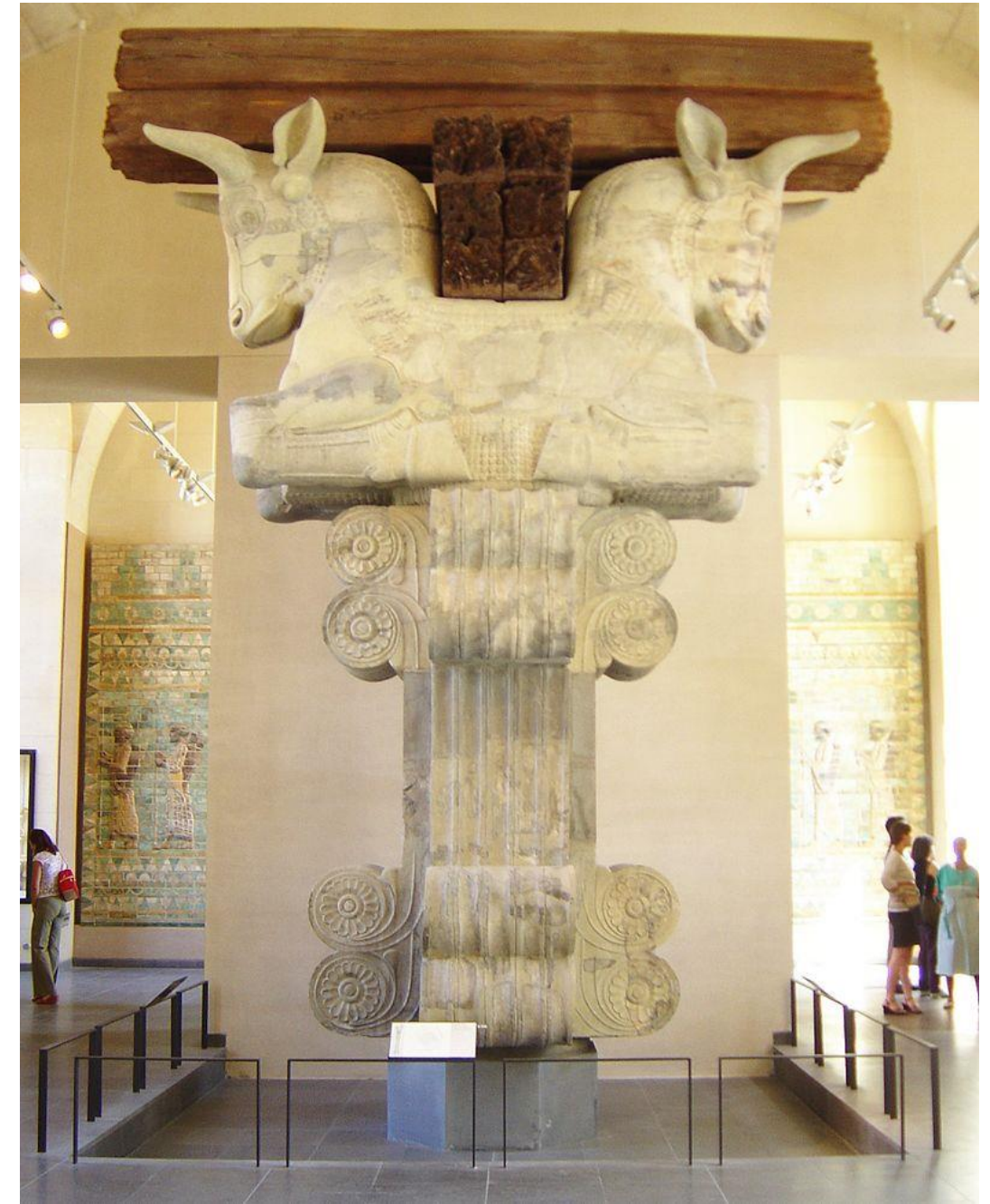

Fuente: 〈https://es.wikipedia.org/wiki/Palacio_de_Susa〉. 
Dadas las dimensiones de la apadana y el uso a que se destinaba, llegando a albergar en recepciones oficiales a unas 10.000 personas, los lados oeste, norte y este de la Apadana disponían de grandes puertas de doble hoja y protegidas por pórticos, con dos hileras de seis esbeltas columnas cada uno ${ }^{16}$.

Hay fuentes que indican la destrucción total de esta ciudad por Alejandro Magno, pero otras dicen que fue respetada, al contrario de lo que sucedió con Persépolis y Pasargadas que realmente fueron arrasadas. Posteriormente, ya en el siglo XIII los mongoles incendiaron Susa y la destruyeron por completo ${ }^{17}$.

\section{Palacio de Persépolis}

El palacio de Persépolis "la ciudad de los persas" según la denominación griega, era desde el punto de vista de diseño, un ecléctico y sofisticado complejo de edificios hipóstilos destinados a suntuosas recepciones, actividades protocolarias y emblemáticas de la actividad política. Iniciado por Darío I el año 515 a. C. y terminado por su hijo y sucesor Jerjes I, sobre el año 450 a. C., tenía una terraza natural donde se asentaba era vastísima y se extendía hasta un acantilado (figura 10).

Figura 10. Perspectiva del Palacio de Persépolis. La apadana en primer término y al fondo la sala "Talar-i-Takht"

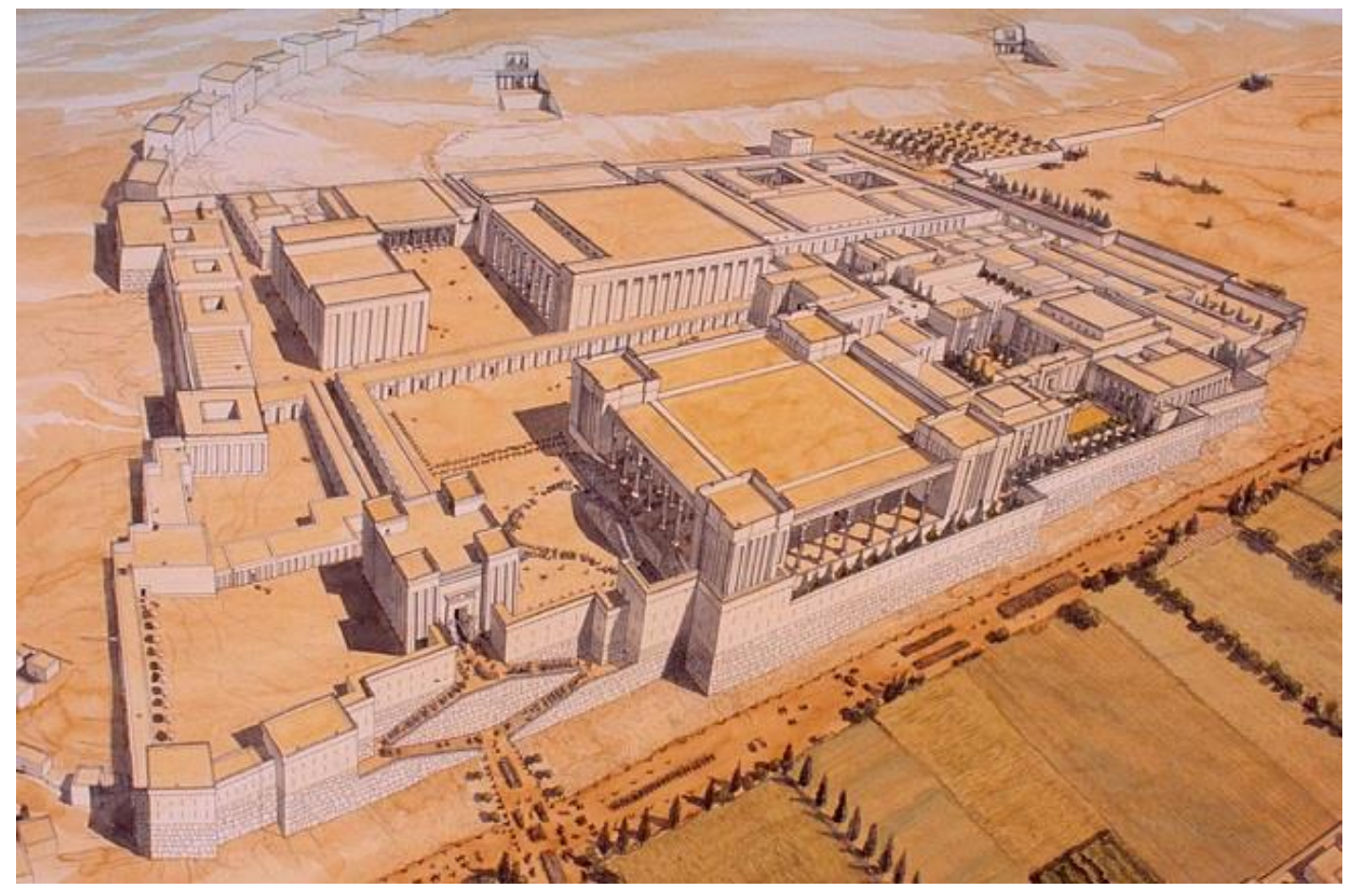

Fuente: Jean-Claude Golvin <https://historiaeweb.com/2019/05/06/alejandro-magno-persepolis/> .

\footnotetext{
${ }^{16}$ Akrópolis. História Antigua <https://akropolishistoria.wordpress.com/2016/06/02/el-friso-de-los-arqueros-desusa/>; De la Llave Muñoz, 2019 <https://es.slideshare.net/sergidelallave/arte-persa-127089915>.

${ }^{17}$ Iran Negin Travel <https://irannegintravel.com/es/destacados-de-iran/palacio-de-apadana-en-susa>; Fernando Blázquez, La Vanguardia, 05/06/2020 <https://www.lavanguardia.com/historiayvida/historiaantigua/20200605/481571901329/susa-iran-elemitas-persia-arqueologia-expolio.html>.
} 
De este complejo palaciego de Jerjes I, sobresale la deslumbrante sala hipóstila llamada "Talar-i-Takht", conocida como la Sala de las 100 Columnas, denominación exacta, puesto que estas se disponían en 10 hileras de 10 y cuya perspectiva se muestra en la figura 10.

En la apadana, menos extensa, la estructura arquitrabada estaba compuesta por 36 columnas, lo hacían en 6 hileras de 6 . El alto nivel técnico y cultural alcanzado por los persas tanto en el Palacio o Tachara, como la Apadana, son además una demostración de funcionalidad, racionalización geométrica y equilibrio: el plano cuadrado del palacio es sistematizado y las columnas -de fuste alto y esbelto en contraste con el egipcio- son estrictamente colocadas.

El techo del palacio, que alcanzaba 20 metros de altura, estaba sostenido por dinteles que descansaban sobre las habituales columnas con capiteles en forma de prótomos de toros y leones. Los prótomos, opuestos el uno al otro, siempre formaban un banco sobre el que descansaba a modo de arquitrabe, una viga principal. Las vigas transversales habían sido situadas directamente sobre las cabezas de los animales y estabilizadas por las orejas o los cuernos.

La utilización de tejados ligeros de cedro sobre las columnatas de juste jónico, permitían la liberación de un espacio importante para el uso, dado que el intercolumnio, o sea, la separación de las columnas es de 8,9 metros. La arquitectura persa consigue en su eclecticismo armonizar la doble función utilitaria y emblemática, y su originalidad de su diseño fue resultante de la combinación de elementos arquitectónicos adquiridos de diversas civilizaciones que fueron sometidas por el Imperio Persa, y la exuberancia arquitectónica de Persépolis muestra numerosos elementos que atestiguan estos orígenes múltiples.

De hecho, con la inclusión de Jonia en el imperio persa en tiempos de Darío I, la arquitectura aqueménida estuvo marcada por una fuerte influencia de la Grecia jónica, la del Asia Menor hoy Turquía- particularmente visible en las salas hipóstilas y los pórticos de los palacios de Persépolis. Arquitectos lidios y jonios fueron contratados para las obras de las dos ciudades persas que estamos estudiando, Susa y Persépolis, diseñando los elementos fundamentales de éstas y jugando así un papel principal en la eclosión del estilo persa. La participación de griegos en la elaboración y erección de columnas, y en el ornamento de palacios en Persia se menciona en inscripciones de Susa, así como en citas del escritor romano Plinio el Viejo (siglo I). Las columnas de la Apadana de Persépolis son jónicas, pero con un fuste más acanalado y delgado de lo habitual, porque su diámetro es inferior a la décima parte de su altura. En Grecia esta rareza la encontramos en las columnas del templo de Hera en la isla de Samos. También algunos capiteles persas llevan grifos mitológicos realizados en bronce ${ }^{18}$.

\section{Grecia y la arquitectura político-artístico-civil}

En la Grecia clásica, es el templo la forma arquitectónica más reconocible. El más antiguo data de los últimos años del siglo VII a. C., fue dedicado a Atenea Pronaia en Delfos; desde entonces se edificaron una infinidad y actualmente se encuentran en distintos estados de conservación. La arquitectura griega por tanto utilizó este motivo, esta función religiosa, para

\footnotetext{
${ }^{18}$ Se denominan grifos mitológicos los animales legendarios que encontramos en la arquitectura arcaica griega. Nuevatribuna.es <https://www.nuevatribuna.es/articulo/historia/increible-persepolis-historia-viajes-travelgreciaclasica-persia/20180507145801151619.html>.
} 
desarrollarse. Pero, qué era, ¿qué significaba la religión para la culta y refinada sociedad griega clásica?

Según Herbert Read, la religión griega desarrolló un proceso de racionalización que le llevó a convertirse en filosofía, de tal modo que no tenían conciencia del pecado como alienación divina, ni por tanto del arrepentimiento. No tenían una relación mística con los dioses, porque apoyados en una explicación racional del mundo, podían obviar el sentido o la naturaleza de la vida o su finalidad y dedicarse a ella con libertad y plenitud ${ }^{19}$.

En este contexto, aunque los griegos concebían los templos como monumentos a la comunidad, los edificios civiles, partiendo de la misma estética, eran utilizados para actividades sociales. Estos lugares de congregación no se habrían producido sin un sistema político donde se tuviera por costumbre la reunión de los ciudadanos, independientemente de la capacidad de decisión que estos poseyeran. A esto añadimos que, difícilmente en Grecia se hubieran construido teatros, tan frecuentes en estas latitudes y en esta época, si no se hubiera desarrollado el género literario.

Sobre todo, hasta la época helenística, los edificios griegos de uso público, teatros orfeones, incluso las ágoras, por ser elementos de uso e identidad cultural, poseen unas dimensiones funcionales, "humanas", frente a la desorbitada magnitud de las construcciones persas o egipcias $^{20}$. En palabras de Jerome Jordan Pollitt "el hombre era quien daba la medida, y las cosas habían de medirse a la luz de su experiencia" 21.

De las cuantiosas y diferenciadas construcciones públicas producidas en la Grecia clásica, analizamos la Estoa (construcción porticada) del Agora de Atenas, la sala de conciertos conocida como el Odeón de Pericles y el Thersilion de Megalópolis, que fue la Sala de Asambleas de la Liga Arcadia. Es una síntesis necesaria, considerando que todas ellas estaban orientadas a un uso civil, artístico y popular.

\section{Estoa de Átalo}

El ágora de Atenas era un espacio bastante cuadrado, aunque irregular y abierto, donde se realizaban todo tipo de actividades públicas como impartir justicia, prácticas administrativas, políticas, comerciales y sociales. Naturalmente como espacio abierto, para nuestro estudio carece de interés, pero las ágoras están rodeadas por un cúmulo de edificios públicos con inmensos pórticos llamados estoas y ésto sí nos parece interesante analizar.

La llamada Estoa de Átalo, espléndido edificio civil, situada en la parte oriental del ágora de Atenas, fue construida por el rey de Pérgamo, Átalo II, (159 a 138 a.C.). Tiene dos plantas de altura y un diseño característico de la época helenística, con grandes dimensiones, unos 112 metros de largo por 19 de ancho. Es un espacio hipóstilo con doble fila de columnas, la exterior es de orden dórico, con los fustes acanalados, pero solo a partir de unos 2 metros, para evitar roturas por el continuo uso, mientras que la fila interior es jónica, con fustes lisos y con las volutas espirales características. En la planta superior las columnas, son solo exteriores, con antepechos, menores de altura y también de orden jónico (figura 11).

\footnotetext{
${ }^{19}$ Read, 1973, p. 92-93.

${ }^{20}$ Gilmart, $2013<$ https://historicodigital.com/arquitectura-publica-griega.html>

${ }^{21}$ Pollitt, 1984, p. 69.
} 
Originalmente contenía 42 tiendas y durante más de tres siglos fue el principal establecimiento comercial del ágora, pero también se trataba de un espacio de convivencia, para reuniones y discusiones, resguardados del sol, del frío y de la lluvia. Si relacionamos los usos a que se destinó la estoa, y la forma que adquirió para tales funciones, no podemos menos que admirar el acierto, observando la funcionalidad, la armonía y la elegancia conseguidas.

Figura 11. Estoa de Átalo

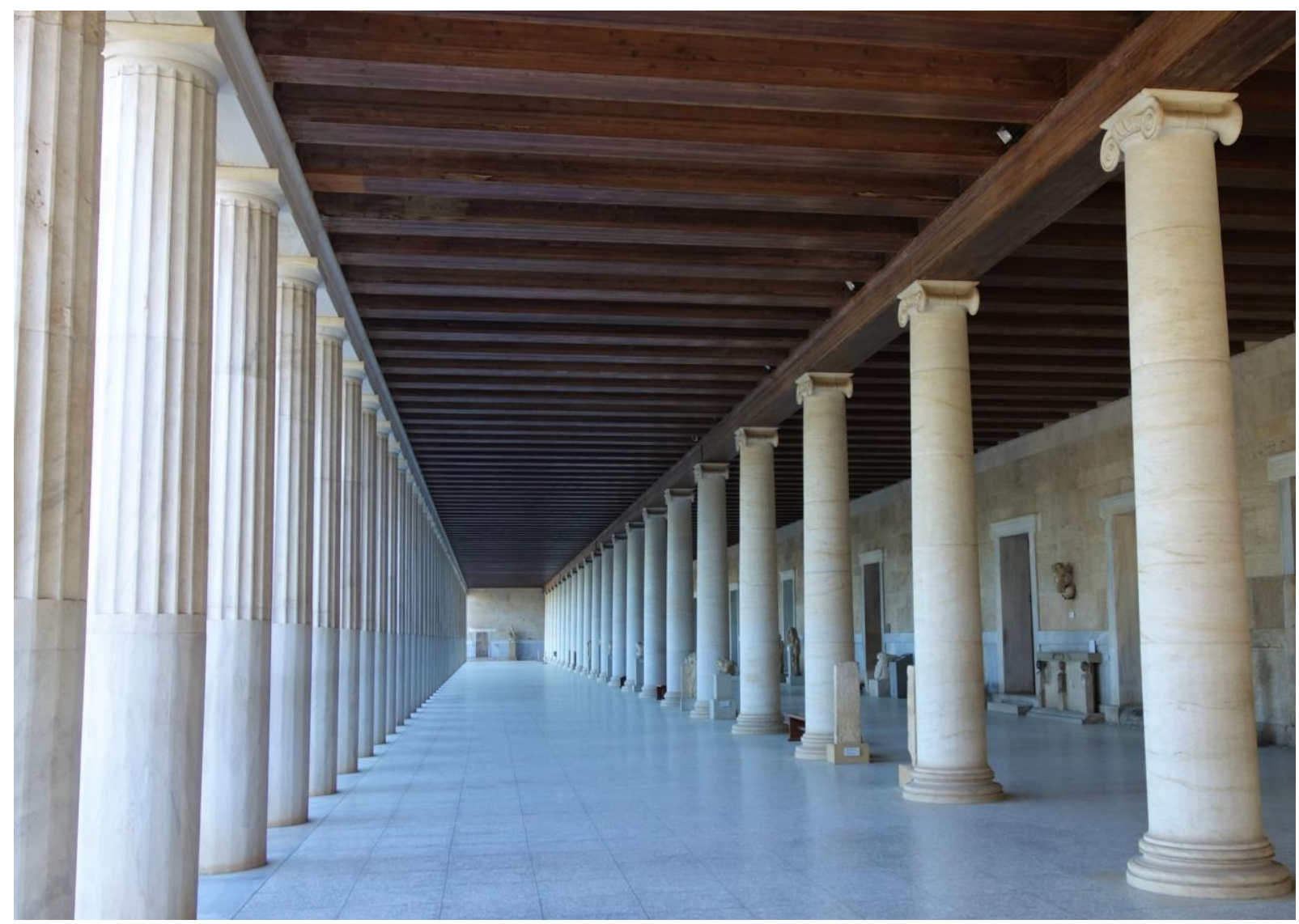

Fuente: Foto del autor

Nos congratulamos de que este magnífico edificio, importante testimonio de la arquitectura civil griega fuera restaurado entre los años 1953 y 1956, por la Escuela Americana de Arqueología de Atenas, con la financiación de John Rockefeller Jr.

\section{Odeón de Pericles}

El "Odeón de Pericles", nombre con el que era conocido este Odeón ubicado en Atenas. Fue un edificio hipóstilo destinado a representaciones teatrales y musicales, construido entre 446442 a. C., en la época helenista, -no la helenística de la Estoa de Átalo- la de mayor esplendor de la Grecia clásica, la época del Partenón de la Acrópolis de Actino, Calícrates y Fidias. Se considera que fue el primer teatro-edificio permanente, techado, dedicado a la actuación, y el primer teatro construido en la ladera sur de la acrópolis. También se celebraban en él conferencias políticas, filosóficas y literarias. Se cree que se mantuvo durante más de tres 
siglos y fue considerado como una de las maravillas arquitectónicas de la antigua Atenas ${ }^{22}$ (figura 12).

Figura 12. Odeón de Pericles

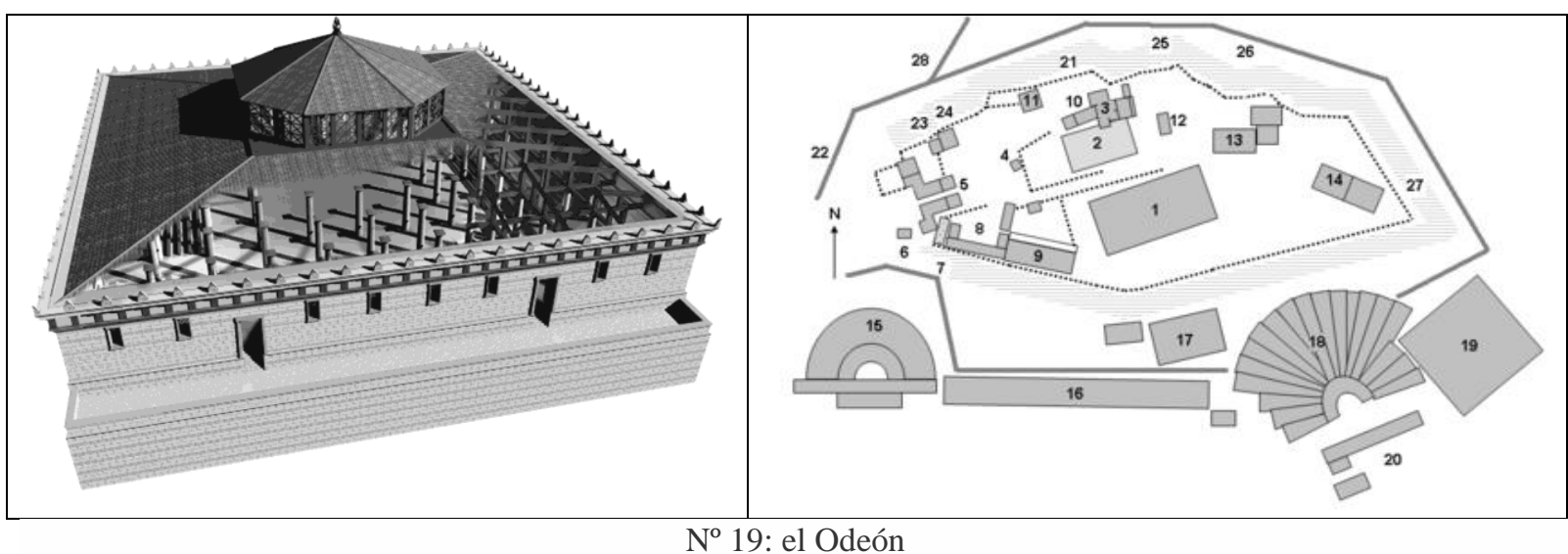

Fuentes: 〈https://es.wikipedia.org/wiki/Ode\%C3\%B3n_de_Pericles>,

$<$ https://www.researchgate.net/figure/Computer-model-of-the-Odeon-of-Pericles_fig1_297839529>.

Producido en gran parte con madera, el odeón fue incendiado por el defensor de la ciudad Aristion, en el año 86 a. C. durante la primera guerra mitridática, para evitar que el sitiador romano Lucio Cornelio Sila, utilizase sus materiales estructurales para atacar la acrópolis. Poco después, hacia el año 60 a. C. fue reedificado por Ariobarzanes II, siguiendo los mismos planos, esta vez todo de piedra, y sobre las columnas se entabló una cubierta piramidal de inspiración persa, como ya hemos mencionado. Según un análisis de Donald Struan Robertson,

Debe de haber tenido azoteas y galerías, pero el piso era horizontal, salvo los asientos levantados contra los muros exteriores. Poseía una superficie de unos 4.000 metros cuadrados, y su entrada principal consistía aparentemente en un propíleo en el lado occidental...se pensó durante mucho tiempo, a partir de los testimonios literarios, que era circular, pero recientes excavaciones han demostrado que se trataba de un amplio edificio rectangular, parecido en parte al Telesterion. Aunque el muro sur se ha perdido, parece que era probablemente un cuadrado de algo más de 61 metros de lado, que contendría alrededor de 80 columnas (quizá nueve por nueve) dispuestas como en Eleusis. Plutarco lo describe como, con muchos asientos y columnas en su interior ${ }^{23}$.

Aunque ya no está en pie, las excavaciones recientes han revelado que el sitio exacto del Odeón es la esquina sureste de la Acrópolis, en el recinto sagrado dionisiaco. Este enclave es muy significativo, recordemos que, en la mitología helénica, Dionisio era dios de la vendimia y del vino, representaba lo terrenal, la sensualidad desatada, y fue amante de Afrodita.

\footnotetext{
${ }^{22}$ Gilmart. Histórico Digital, 2013 <https://historicodigital.com/arquitectura-publica-griega.html>; Dickinson College Commentaries <http://dcc.dickinson.edu/images/odeon-pericles-architectural-cut-away>.

${ }^{23}$ Robertson, 1981, p. 172.
} 


\section{Thersilion de Megalópolis}

Edificado en la Arcadia, región del Peloponeso Central, entre los años 371 y 368 a. C., el Thersilion fue una Sala de Asambleas con la cubierta construida mediante arquitrabes, sobre 65 columnas dóricas. Este enorme espacio hipóstilo era rectangular, más ancho que largo, $(66,64$ x 52,42 metros) y con capacidad para 8.700 personas sentadas en bancos de madera colocados por todo el perímetro.

Tenía el acceso por un pórtico centrado con columnas, que conducía a tres puertas del edificio y desde el interior de este, había una salida a la orquestra (zona circular de un teatro contiguo, donde se colocaba el coro). Las columnas, de capitel dórico, tienen una clara influencia jónica -dada la época helenística de su construcción- y siguen una lógica geométrica, mediante la cual, la obstrucción que pudieran producir éstas, se reduce al mínimo y el centro es prácticamente visible desde todos los puntos de la sala (figura 13).

Figura 13. Plano de planta del Thersilion de Megalópolis
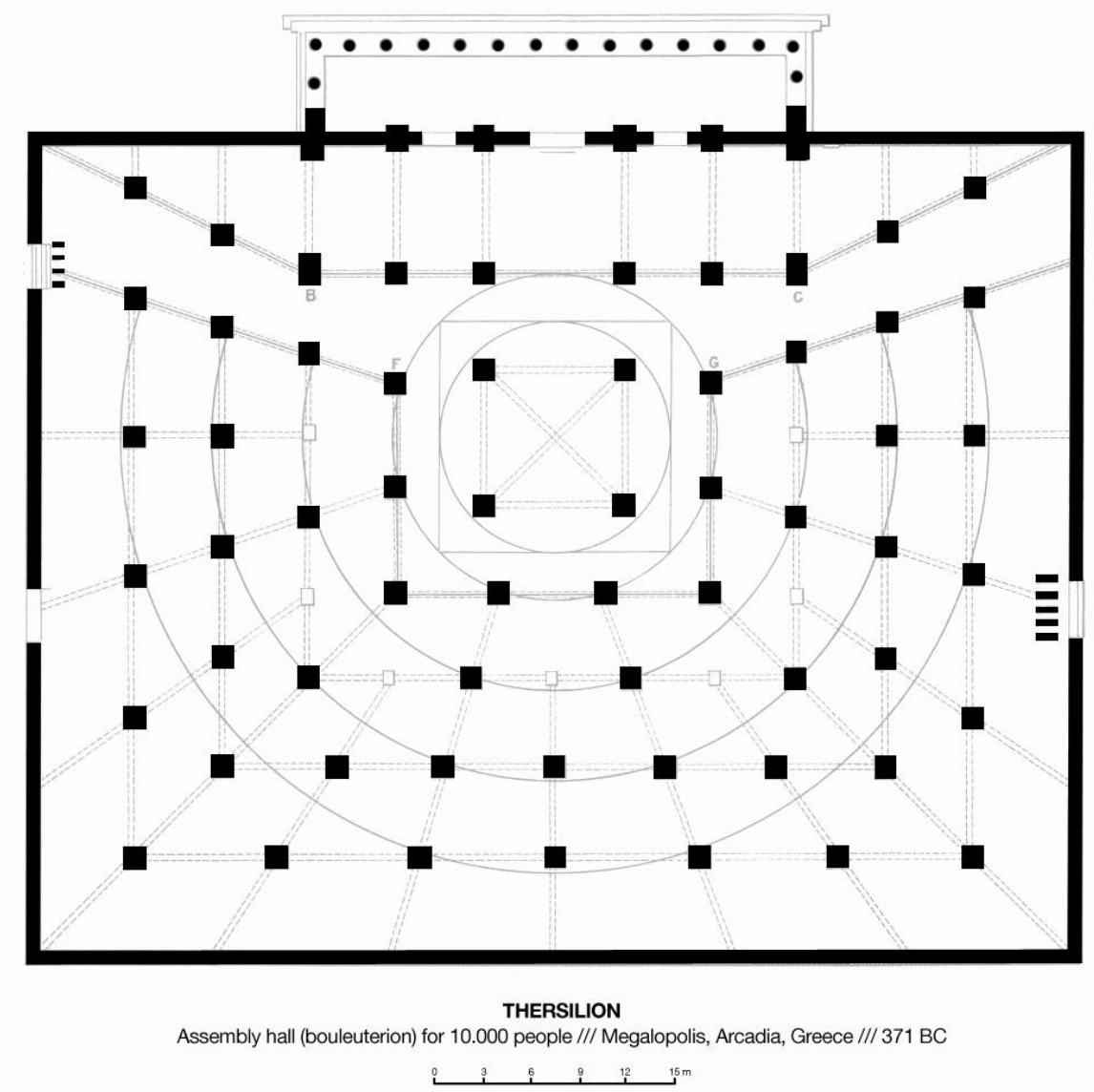

Fuente: Daniel Tudor Munteanu <https://cargocollective.com/danielmunteanu/Thersilion>. 
Robertson, en su estudio sobre arquitectura griega y romana, pensando en el uso para el que fue construido el Thersilion dice "estaba mucho mejor diseñado de acuerdo con las necesidades de una amplia asamblea, que el Odeón de Atenas o el Telesterion de Eleusis"24.

Es sorprendente, ver como la Arcadia, con el tiempo, se ha convertido en un país imaginario, descrito por diversos artistas. La mitología griega sirvió al poeta romano Virgilio (70 al 19 a. C.) para inspirar sus Bucólicas, una serie de poemas situados en esta región. También en el Renacimiento, Gracilaso de la Vega, trata frecuentemente el tema, asimilándolo al propio paraíso, porque "Arcadia" es presentada como un modo de vida natural ${ }^{25}$.

\section{Conclusión}

En nuestro análisis de las salas hipóstilas de la antigüedad, desde las del complejo funerario egipcio de Zóser de 2650 a. C., pasando por la Persia y la Grecia clásicas, hasta las edificadas por el primer emperador romano Augusto, 63 a. C. al 14 d. C. ${ }^{26}$, hemos observado la diversidad e incluso la disparidad de las formas y los usos, y nos reafirmamos en considerar que cada necesidad funcional, de modo muy coherente, provocó las diferentes soluciones estéticas.

Hoy está aceptado mayoritariamente el principio del diseño funcionalista, asociado a la arquitectura moderna del siglo XX, que nos indica que, para atender las necesidades de uso, el proyectista debe configurar la forma a partir de la función específica a que se dedica el edificio. El arquitecto racionalista Louis H. Sullivan (1856-1924) manifestó a finales del siglo XIX que todas las cosas que existen tienen una forma que nos explica lo que son y que las hace diferentes del resto, e ideó la frase "la forma sigue a la función" aseverando que ambas, la función o el uso y la forma interactúan formando una unidad orgánica.

Pero el propósito de este escrito es demostrar que ya, en el diseño de las salas hipóstilas clásicas de los tres vértices geográficos (también vértices culturales y estéticos), se observa, desde un principio, esta "unidad orgánica", donde la función y la forma, son aspectos que se encuentran en una relación constante. La producción de los espacios hipóstilos para cada uso concreto y el diseño de la forma que estos adquieren se convirtieron en algo interactivo y recíproco, ya desde los del complejo funerario edificado por el Inhotep, prácticamente al principio de la historia de la arquitectura.

Las salas hipóstilas de los templos egipcios, al utilizarse como acceso a los recónditos lugares sagrados, podría parecer que detentaran una función secundaria, pero estas salas columnadas y su grandiosidad, su gran contenido artístico representativo, simbólico y místico, realizado mediante bajorrelieves y pinturas que hablan del poder imperial de los faraones, de sus hazañas - ciertas o imaginarias- las hace absolutamente protagonistas ${ }^{27}$, también porque ostentan una unidad orgánica en la representación de la simbiosis religión-estado.

En la Persia Aqueménida, las elegantes salas hipóstilas de las apadanas, de Persépolis, Susa y Pasagardas, por su función palaciega, reúnen características de fastuosidad con propíleos de acceso, "protegidos" con toros alados, que los persas copiaron de la cultura asiria. Las columnas persas están rematadas por unos originales y complicados capiteles que son muy

\footnotetext{
${ }^{24}$ Robertson, 1981, 173.

${ }^{25}$ Fabrizi y Lucarelli, 2018 <http://socks-studio.com/2018/12/27/the-thersilion-in-megalopolis-greece-370-bce/>

${ }^{26}$ Pijoan, 1964, vol. I, p. 275-276.

${ }^{27}$ Sapientiae Lux (Ars) <https://www.edugoro.org/arte/wp-content/uploads/2015/02/egipto.pdf>.
} 
característicos, que no tienen precedente en ningún otro estilo, son altas y muy esbeltas en contraste con las egipcias ${ }^{28}$. La función representativa para la que fueron edificadas, produjo unas formas complejas y muy sofisticadas. Al tener el poder terrenal (político) el dominio de la sociedad sin interferencias religiosas, su unidad orgánica es puramente aristocrática.

Los templos griegos en cierta manera, eran monumentos a la comunidad, una demostración insigne de su grandeza, de su conciencia como pueblo y de su poder ${ }^{29}$. Los edificios civiles mantenían la misma estética, pero con modificaciones estructurales y morfológicas en interiores y exteriores debidas al cambio de uso. Las plantas pierden las proporciones regladas de los templos, se hacen casi cuadradas y se omite la cella para la diosa o el dios correspondiente, y en su lugar se habilita un gran espacio hipóstilo con hileras de asientos en tribunas laterales escalonadas, que son ocupadas por la población, en asambleas, representaciones teatrales y conciertos. Hemos puesto como ejemplo de estas edificaciones civiles, la estoa del ágora de Atenas, el Odeón o Sala de Conciertos de Pericles y el Thersilion $^{30}$.

Aunque con esta morfología o similar, también se edificaron para uso civil, el Telesterion en Eleusis, el Bouleuterion en Mileto, o la Sala Hipóstila en Delos. El paganismo griego, de cariz naturalista, humanista y filosófico, permitió que pudiera hacerse una traslación de la arquitectura de uso religioso a la dedicada a funciones civiles, tanto legislativas o políticas, como culturales y artísticas. De este modo las salas hipóstilas de la Grecia clásica adquieren unidad orgánica en su uso democrático y popular.

Cuando planteamos esta discusión, quisimos hacerlo desde los tres ámbitos históricos clásicos que sabemos son más relevantes, el religioso-funerario egipcio, el imperial persa y el cívicocultural griego, y hemos analizado la disparidad de las soluciones formales adoptadas en cada localización, la riqueza y la sorprendente originalidad de los resultados, hecho al que paradójicamente ha contribuido el constante intercambio cultural y artístico.

\section{Bibliografía}

ARTEESPAÑA. Arquitectura Mesopotámica $<$ https://www.arteespana.com/arquitecturamesopotamica.htm>.

ARTEESPAÑA. Templos egipcios <https://www.arteespana.com/templosegipcios.htm>.

AKRÓPOLIS. Historia Antigua. El friso de los arqueros de Susa $<$ https://akropolishistoria.wordpress.com/2016/06/02/el-friso-de-los-arqueros-de-susa/>.

ASIMOV, Isaac. Los griegos: una gran aventura. Madrid: Alianza Editorial, 2011.

BLÁZQUEZ, Fernando. Susa, el Louvre y las iras de Donald Trump. La Vanguardia, $05 / 06 / 2020$ $<$ https://www.lavanguardia.com/historiayvida/historiaantigua/20200605/481571901329/susa-iran-elemitas-persia-arqueologia-expolio.html> .

\footnotetext{
${ }^{28}$ Pijoan, 1964, vol. I, p. 113.

${ }^{29}$ Finley, 1980, p. 49.

${ }^{30}$ Robertson, 1981, p. 173.
} 
Blog de viajes de Rafael Gómez. Persépolis <https://micamara.es/persepolis/>.

DE LA LLAVE MUÑOZ, Sergio. El Arte persa. Historia del Arte Antiguo en Egipto y $\begin{array}{lllll}\text { Oriente Próximo. Talavera de la Reina: } & 2019\end{array}$ <https://es.slideshare.net/sergidelallave/arte-persa-127089915>.

DICKINSON COLLEGE COMMENTARIES. The Odeon of Pericles Architectural CutAway <http://dcc.dickinson.edu/images/odeon-pericles-architectural-cut-away>.

EGIPCIOLOGIA.ORG. El Tiemplo de Hathor (Dendera). La Tierra de los Faraones. <https://egiptologia.org/?page_id=1392>.

FABRIZI, Mariabruna; LUCARELLI, Fosco. The Thersilion in Megalopolis, Greece (370 BCE). Microcities Socks-Studio, $2018<\mathrm{http}$ ///socks-studio.com/2018/12/27/the-thersilion-inmegalopolis-greece-370-bce/>.

FINLEY, Moses I. Los griegos de la antigüedad. Barcelona: Labor, 1980.

GARCÍA ÁVILA, Manuel Blas. La artesanía creativa en España: una vuelta a la materia. Biblio 3W. Revista Bibliográfica de Geografía y Ciencias Sociales, Vol. XII, nº 742, 15 de agosto de 2007 <http://www.ub.es/geocrit/b3w-742.htm>.

GILMART, D. Arquitectura pública griega. Histórico Digital, 2013 <https://historicodigital.com/arquitectura-publica-griega.html>.

GOLVIN, Jean-Claude. Reconstrucción digital fiel de los palacios de Persépolis. Historiae. <https://historiaeweb.com/2019/05/06/alejandro-magno-persepolis/>.

GLOSARIO ILUSTRADO DE ARTE ARQUITECTÓNICO $<$ https://www.glosarioarquitectonico.com/wp-content/uploads/2015/12/columnas-egipcias1.jpg>.

IRAN NEGIN TRAVEL. Palacio de Apadana en Susa $<$ https://irannegintravel.com/es/destacados-de-iran/palacio-de-apadana-en-susa>.

LULL, José. El templo de Karnak: El gran santuario de Amón. National Geographic <https://historia.nationalgeographic.com.es/a/templo-karnak-gran-santuario-amon_6312>.

POLLIT, Jerome Jordan. Arte y experiencia en la Grecia Clásica. Bilbao: Xarait Ediciones, 1984.

MASDEARTE.COM. Louis Sullivan, la forma sigue a la función $<$ https://masdearte.com/especiales/louis-sullivan-la-forma-sigue-la-funcion/>.

LÓPEZ, Francisco. El templo de Hathor en Dendera, 2003 $<$ https://megaconstrucciones.net/?construccion=templo-dendera $>$.

MENFIS TOUR. Los templos de Abu Simbel en Egipto $<$ https://spain.memphistours.com/Egipto/sobre-egipto/atracciones-en-asuan/wiki/los-templosde-abu-simbel>. 
NUEVATRIBUNA.ES. La increíble Persépolis

$<$ https://nuevatribuna.publico.es/articulo/historia/increible-persepolis-historia-viajes-travelgreciaclasica-persia/20180507145801151619.html>.

PIJOAN I SOTERAS, Josep. Historia del arte. Barcelona: Salvat Editores, 1964, vol. 1.

READ, Herbert. Arte y Sociedad. Barcelona: Ediciones Península, 1973.

ROBERTSON, Donald Struan. Arquitectura Griega y Romana. Madrid: Ediciones Cátedra, 1981.

SAPIENTIAE LUX (Ars). Arte Egipcio <https://www.edugoro.org/arte/wpcontent/uploads/2015/02/egipto.pdf>.

TUDOR MUNTEANU, Daniel. Thersilion <https://cargocollective.com/danielmunteanu/Thersilion>.

VITRUVIO, Marco Lucio. Los Diez Libros de Arquitectura. Barcelona: Editorial Iberia, 1982.

WIKIPEDIA.ORG <https://es.wikipedia.org/wiki/Palacio_de_Susa>.

Ficha bibliográfica:

GARCÍA ÁVILA, Manuel-Blas. Diseño y función de las salas hipóstilas clásicas. El triángulo Egipto, Persia y Grecia. Ar@cne. Revista Electrónica de Recursos de Internet sobre Geografia y Ciencias Sociales. Barcelona: Universidad de Barcelona, I de noviembre de 202I, vol. XXV, $n^{\circ}$ 260. DOI: https://doi.org// 0.1344/ara2021.260.36990

\section{Menú Geo Crítica}

